\title{
Clinical characteristics at initial presentation and impact of dual therapy on the outcome of bacteremic Streptococcus pneumoniae pneumonia in adults
}

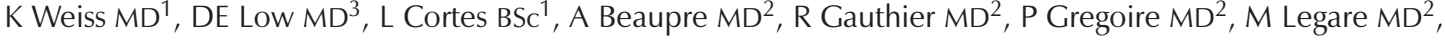 \\ F Nepveu $M D^{2}$, D Thibert $M D^{2}, C$ Tremblay $M D^{2}$, J Tremblay $M D^{2}$
}

\begin{abstract}
K Weiss, DE Low, L Cortes, et al. Clinical characteristics at initial presentation and impact of dual therapy on the outcome of bacteremic Streptococcus pneumoniae pneumonia in adults. Can Respir J 2004;11(8):589-593.
\end{abstract}

BACKGROUND: Approximately 10\% of patients hospitalized with community-acquired pneumonia (CAP) are bacteremic. Bacteremic Streptococcus pneumoniae pneumonia (BSPP) is the number one cause of mortality, representing up to $70 \%$ of all CAP deaths. In fact, all CAP guidelines have identified this issue as one of the most important issues when establishing their recommendations.

OBJECTIVE: To assess the impact of dual antibiotic therapy in patients with BSPP.

PATIENTS AND METHODS: All cases of BSPP in patients 18 years of age and older who were hospitalized from 1995 to 2000 were retrospectively analyzed. The standard initial therapeutic regimen used was cefuroxime with or without a macrolide from 1995 to 1997, and ceftriaxone and azithromycin or clarithromycin from 1998 to 2000. During the 1995 to 1997 period, only $16 \%$ of the patients initially received a macrolide, whereas all patients in the 1998 to 2000 period received a macrolide at admission.

RESULTS: Ninety-five patients (49 men, 46 women) with a mean age of 63 years (range 20 to 98 years) were included in the present study. The mean pneumonia severity index at admission was 113 for the monotherapy cohort and 114 for the dual therapy group.

At admission, $30.5 \%$ of patients had a leukocyte count greater than $20 \times 10^{9} / \mathrm{L}, 11.5 \%$ had a systolic blood pressure less than $90 \mathrm{mmHg}$, $44.2 \%$ had a respiratory rate greater than 30 breaths/min and $33.6 \%$ had nausea/vomiting, necessitating some form of therapy or preventing the patient from eating. In addition, $16.8 \%$ had no fever at admission. Overall, $72.5 \%$ became afebrile within 48 h. Fifteen (15.8\%) patients died (four within the first $72 \mathrm{~h}$ ). The mortality rate was significantly higher in the monotherapy group (11 of 42 patients; $25.6 \%$ ) than in the dual therapy cohort (four of 53 patients; $7.5 \%$ ) (OR 0.23; 95\% CI 0.07 to 0.74). Antibiotic resistance was not associated with increased mortality.

CONCLUSION: The combination of ceftriaxone plus a macrolide significantly reduced the mortality rate compared with monotherapy (cefuroxime) in patients with CAP that have the highest mortality rate.

Key Words: Bacteremia; Pneumonia; Streptococcus pneumoniae
Les caractéristiques cliniques à la présentation et les répercussions de la bithérapie sur l'issue d'une pneumonie à Streptococcus pneumoniae bactériémique chez les adultes

HISTORIQUE : Environ $10 \%$ des patients hospitalisés en raison d'une pneumonie non nosocomiale (PNN) sont bactériémiques. La pneumonie à Streptococcus pneumoniae bactériémique (PSPB) est la principale cause de mortalité, représentant jusqu'à $70 \%$ des décès secondaires à une PNN. En fait, toutes les lignes directrices sur la PNN indiquent dans leurs recommandations qu'il s'agit là de l'un des enjeux les plus importants.

OBJECTIF : Évaluer les répercussions de la bithérapie chez les patients atteints de PSPB.

PATIENTS ET MÉTHODOLOGIE : Tous les cas de PSPB chez des patients de 18 ans et plus hospitalisés entre 1995 et 2000 ont été analysés de manière rétrospective. Le schéma thérapeutique initial standard utilisé était de la céfuroxime avec ou sans un macrolide entre 1995 et 1997, et de la ceftriaxone et de l'azithromicine ou de la clarithromycine entre 1998 et 2000. Entre 1995 et 1997, seuls $16 \%$ des patients avaient reçu un macrolide au départ, tandis qu'entre 1998 et 2000, tous les patients ont reçu un macrolide à l'hospitalisation.

RÉSULTATS : Quatre-vingt-quinze patients (49 hommes, 46 femmes) d'un âge moyen de 63 ans (fourchette de 20 à 98 ans) ont été inclus dans l'étude. L'indice moyen de gravité de la pneumonie à l'hospitalisation était de 113 dans la cohorte sous monothérapie et de 114 dans celle sous bithérapie. À l'hospitalisation, 30,5\% des patients présentaient une numération leucocytaire supérieure à $20 \times 10^{9} / \mathrm{L}, 11,5 \%$ présentaient une tension artérielle systolique inférieure à $90 \mathrm{mmHg}, 44,2 \%$ affichaient un rythme respiratoire supérieur à 30 respirations à la minute et $33,6 \%$, des nausées ou des vomissements nécessitant une forme de traitement ou empêchant le patient de manger. De plus, 16,8 \% n'étaient pas fiévreux à l'hospitalisation. Dans l'ensemble, 72,5\% étaient devenus afébriles au bout de 48 heures. Quinze $(15,8 \%)$ patients sont décédés (dont quatre dans les 72 premières heures). Le taux de mortalité était beaucoup plus élevé au sein du groupe sous monothérapie (11 des 42 patients, ou 25,6\%), qu'au sein de celui sous bithérapie (quatre de 53 patients, ou 7,5\%) (RR 0,23; $95 \%$ IC 0,07 à 0,74). L'antibiorésistance n'était pas associée à une augmentation de la mortalité.

CONCLUSION : L'association de ceftriaxone et d'un macrolide réduisait de manière considérable le taux de mortalité par rapport à une monothérapie (céfuroxime) chez des patients atteints de PNN qui présentent le taux de mortalité le plus élevé.

${ }^{1}$ Department of Microbiology and Infectious Diseases; ${ }^{2}$ Division of Respirology, Maisonneuve-Rosemont Hospital, University of Montreal, Montreal, Quebec; ${ }^{3}$ Department of Microbiology, Mount Sinai Hospital, University of Toronto, Toronto, Ontario

Correspondence: Dr K Weiss, Department of Microbiology and Infectious Diseases, Maisonneuve-Rosemont Hospital,

5415 L'Assomption, Montreal, Quebec H1T 2M4. Telephone 514-252-3817, fax 514-252-3898, e-mail weisscan@aol.com 
C rommunity-acquired pneumonia (CAP) still represents a challenge for clinicians. Although the vast majority of CAP is treated in an outpatient setting, approximately $20 \%$ of patients need some form of hospitalization (1). In only approximately $50 \%$ of all the cases is an etiological agent identified (1). Probably the most feared and respected form of CAP among clinicians is a bacteremic Streptococcus pneumoniae pneumonia. A larger proportion of patients with $S$ pneumoniae pneumoniae have bacteremia than patients with CAP caused by other microorganisms (1). Marrie (2) stated that approximately $10 \%$ of all admitted patients with CAP have positive blood cultures, with $S$ pneumoniae representing $60 \%$ of these cases. In another review of 12 series of CAP cases admitted to hospitals (3), 330 of 2935 (11\%) patients had bacteremia, with $\mathrm{S}$ pneumoniae accounting for $67 \%$ of the cases. S pneumoniae is the most common cause of death in CAP, accounting for approximately two-thirds of all mortality (4). Although the mortality rate from pneumococcal pneumonia has been reduced over the past decades, bacteremic pneumococcal pneumonia remains as lethal as ever despite improved care. Several factors, such as an aging population and more immunocompromised patients, may explain this finding (5-6).

Several guidelines $(1,7,8)$ have been published over the past few years with regard to CAP. All considered the increasing antibiotic resistance among $S$ pneumoniae strains. For hospitalized patients, single monotherapy with fluoroquinolones is recommended by most groups, but dual therapy combining beta-lactams and a macrolide still represents a good choice $(1,7)$. Emerging data suggest that dual therapy may be superior for bacteremic S pneumoniae pneumonia (9-10). Published data (11) suggest that a non-negligible proportion of patients with bacteremic S pneumoniae pneumonia have a concomittant Mycoplasma pneumoniae or Legionella species (rarely) infections. The recent publication of failures with fluoroquinolones and macrolides $(11-14)$ raise the issue of the increase in clinically significant resistance to these classes of antibiotics.

The objective of the present study was to assess the clinical characteristics of adult patients presenting with bacteremic $S$ pneumoniae pneumonia and to evaluate the impact of initial dual antibiotic therapy on mortality.

\section{METHODS}

\section{Design of the study}

A retrospective study on all cases of bacteremic $S$ pneumoniae pneumonia in a 600-bed tertiary care centre was performed. Using the microbiology data bank, all patients aged 18 years and older from January 1995 to December 2000 with at least one positive blood culture with $S$ pneumoniae were screened.

\section{Inclusion and exclusion criteria}

Only patients over 18 years of age with a confirmed diagnosis of pneumonia associated with bacteremia were included in the study. Pneumonia was defined by the presence of at least two new symptoms in the past 10 days, such as fever (temperature greater than $38^{\circ} \mathrm{C}$ ), hypothermia (temperature less than $36^{\circ} \mathrm{C}$ ), cough, sputum production, increased dyspnea, pleuritic pain and a new infiltrate on the patient's chest x-ray confirmed by a radiologist. Patients with additional infectious complications such as meningitis, abscesses, empyema, septic arthritis or endocarditis were excluded. The criteria for CAP diagnosis were in line with what has been previously published (15). Patients who received more than one dose of any antibiotic other than a beta-lactam or a macrolide within the first $24 \mathrm{~h}$ were also excluded.

All patients were followed for at least 30 days after they were discharged from the hospital.

\section{Antibiotic therapy}

Until 1997, the standard therapeutic regimen at the Maisonneuve-Rosemont Hospital (Montreal, Quebec) was intravenous (IV) cefuroxime (750 mg every $8 \mathrm{~h}$ ) with or without a macrolide. The decision to add a macrolide was left to the attending physician.

Because of increasing side effects associated with cefuroxime therapy (eg, diarrhea and Clostridium difficile colitis), concerns by infectious disease physicians and respirologists of emerging resistance to cefuroxime among $S$ pneumoniae strains in the region (16) and guidelines advocating the use of fluoroquinolones or dual therapy, the standard treatment was changed to ceftriaxone $(1 \mathrm{~g}$ to $2 \mathrm{~g}$ IV every $24 \mathrm{~h}$ ) and a macrolide (azithromycin IV most of the time or oral clarithromycin $500 \mathrm{mg}$ twice a day) in 1998. Dual therapy was defined as the inclusion of a macrolide for at least $48 \mathrm{~h}$ at the initiation of therapy.

Susceptibility testing for S pneumoniae strains was performed by a broth microdilution method using National Committee for Clinical Laboratory Standards criteria and recommendations (17). Statistical analysis was done using either the Student's $t$ test for continuous parameters or $\chi^{2}$ analysis for nonparametric data. OR and 95\% CI were calculated using the Miettinen formula. The Pneumonia Severity Index (PSI), as defined by Fine et al (18), was calculated for each patient at admission.

\section{RESULTS}

Ninety-five patients were included in the study, 49 (51.6\%) men and $46(48.4 \%)$ women. Their mean age was 63 years (range 20 to 98 years); 43 (45.2\%) patients were younger than 59 years of age. Of the total, 50 patients were from the 1995 to 1997 period and 45 patients were from the 1998 to 2000 period. Forty-two patients were treated with one antibiotic (cefuroxime) and 53 patients received dual therapy within the first $48 \mathrm{~h}$ of admission (46 patients received ceftriaxone and macrolide; seven received cefuroxime and macrolide). For the dual therapy group, the numbers were too small to calculate any difference within the group with regard to the choice of beta-lactam.

The mean PSI score was 114 (range 23 to 201); 113 for the monotherapy group and 114 for the dual therapy group. The mean PSI score did not change between the two time periods (113 in 1995 to 1997 and 114 in 1998 to 2000). Sixty-five of 95 patients $(68.4 \%)$ were classified as either class IV or V. On the other hand, 16 of 95 (16.8\%) patients were categorized as classes I or II, for which hospitalization is usually not recommended. Overall, 44.2\% (42 of 95 patients) of all the patients had no significant underlying medical conditions (Table 1).

Twenty-nine of 95 patients $(30.5 \%)$ spent at least $24 \mathrm{~h}$ in the intensive care unit: 13 of $42(30.9 \%)$ in the single therapy group versus 16 of $53(30.2 \%)$ in the dual therapy group. Among the patients who died, eight of 15 were admitted to the intensive care unit. All patients received their first dose of antibiotic within $8 \mathrm{~h}$ of their arrival at the emergency department (mean $3.9 \mathrm{~h}$ ). 
TABLE 1

Number of patients per class according to initial Pneumonia Severity Index (PSI) score, mortality rate and risk factors

\begin{tabular}{lccc}
\hline & Monotherapy group & Dual therapy group & Total \\
\hline Number of patients (\% mortality) & $42(25.6)$ & $53\left(7.5^{\star}\right)$ & $95(15.8)$ \\
Classes I to II, $\mathrm{n}$ (number of deaths [\%]) & $10(0)$ & $6(0)$ & $16(0[0])$ \\
Class III, $\mathrm{n}$ (number of deaths [\%]) & $6(1)$ & $8(0)$ & $14(1[7.1])$ \\
Class IV, $\mathrm{n}$ (number of deaths [\%]) & $14(4)$ & $22(1)$ & $36(5[13.9])$ \\
Class V, $\mathrm{n}$ (number of deaths [\%]) & $12(6)$ & $17(3)$ & 114 \\
PSI score (mean) & 113 & $12(22.6)$ & 114 \\
Chronic obstructive pulmonary disease, $\mathrm{n}(\%)$ & $11(26.1)$ & $16(30.2)$ & $23(24.2)$ \\
Congestive heart failure, $\mathrm{n}(\%)$ & $10(23.8)$ & $9(17.0)$ & $26(27.3)$ \\
Immunosuppression ${ }^{\dagger}, \mathrm{n}(\%)$ & $9(21.4)$ & $20(38.5)$ & $18(18.9)$ \\
None, $\mathrm{n}(\%)$ & $22(52.4)$ & $42(44.2)$ & \\
\hline
\end{tabular}

${ }^{*} P=0.02$; ${ }^{\prime}$ Immunosupression includes HIV-positive and CD4 less than 350, kidney or bone marrow transplant in the past two years, $10 \mathrm{mg}$ or more of oral prednisone or equivalent within the past three months, or recent chemotherapy or radiotherapy (within the past year)

TABLE 2

Initial clinical characteristics of patients with bacteremic Streptococcus pneumoniae pneumonia

\begin{tabular}{lccc}
\hline & Number of patients (\%) & Mean & Range \\
\hline $\begin{array}{l}\text { Leukocytes } \\
\leq 4 \times 10^{9} / \mathrm{L}\end{array}$ & $8(8.4)$ & 15.4 & 0.8 to 47.6 \\
$\quad 20 \times 10^{9} / \mathrm{L}$ & $29(30.5)$ & & \\
$\begin{array}{l}\text { Systolic blood pressure } \\
\leq 90 \mathrm{mmHg}(\%)\end{array}$ & $11(11.6)$ & 120.2 & 60 to 230 \\
$\begin{array}{l}\text { Initial temperature } \\
\quad 35^{\circ} \mathrm{C} \text { or }>40^{\circ} \mathrm{C}\end{array}$ & $15(15.8)$ & 38.4 & 35 to 40.5 \\
$\begin{array}{l}\text { Respiratory rate } \\
>30 \text { breaths } / \text { minute }\end{array}$ & $42(44.2)$ & 28 & 14 to 48 \\
$\begin{array}{l}\mathrm{PaO}_{2}<90 \mathrm{mmHg} \\
\mathrm{Nausea} \text {, vomiting or }\end{array}$ & $43(45.3)$ & 86.7 & 55 to 99 \\
both at admission & $32(33.7)$ & $\mathrm{NA}$ & $\mathrm{NA}$ \\
\hline
\end{tabular}

${ }^{*}$ Necessitating antiemetic treatment or patient was unable to eat. NA Not applicable; $\mathrm{PaO}_{2}$ Partial pressure of $\mathrm{O}_{2}$

A sputum sample meeting the accepted criteria (greater than 10 polymorphonuclear neutrophil leukocytes per low power field, less than 10 squamous cells per low power field) was obtained in only 47 patients $(49.7 \%)$, despite the fact that at least one sputum sample was obtained from all patients. $S$ pneumoniae was isolated in respiratory specimens from only seven patients $(7.3 \%)$.

Mortality was significantly higher in the group receiving monotherapy than in the dual therapy group (11 of 42 patients [25.6\%] versus four of 53 patients [7.5\%], $P=0.02$ ). The number of deaths within the first $72 \mathrm{~h}$ of admission was three and one, respectively. A respiratory rate greater than 30 breaths/minute, which has been recognized as one of the most significant and most reproducible risk factors for severity in patients presenting with CAP, was present in $44.2 \%$ of all the patients at admission (Table 2). In contrast, a systolic blood pressure of less than $90 \mathrm{mmHg}$ was present in only $11.5 \%$ (11 of 95) of all patients; therefore, septic shock was uncommon at presentation (Table 2). In terms of symptom resolution, the vast majority of patients $(72.5 \%)$ became afebrile and hemodynamically stable within $48 \mathrm{~h}$ after the start of therapy. With regard to risk factors, only septic shock at presentation was associated with a significantly higher mortality risk (Table 3 ). Among the five patients with septic shock who died, two patients received dual
TABLE 3

Risk factors associated with mortality in patients with bacteremic Streptococcus pneumoniae pneumonia

\begin{tabular}{lll}
\hline & OR & \multicolumn{1}{c}{$\mathbf{9 5 \%} \mathbf{C I}$} \\
\hline Congestive heart failure & 0.66 & $(0.16$ to 2.36$)$ \\
Chronic obstructive pulmonary disease & 0.41 & $(0.09$ to 1.86$)$ \\
Immunosuppression & 0.38 & $(0.05$ to 2.9$)$ \\
Diabetes & 1.18 & $(0.28$ to 5.03$)$ \\
Age $\geq 60$ years & 1.81 & $(0.57$ to 5.72$)$ \\
Respiratory rate $>30$ breaths $/$ min & 1.33 & $(0.43$ to 4.07$)$ \\
Chronic renal failure & 1.38 & $(0.27$ to 7.04$)$ \\
Septic shock & 6.17 & $(1.78$ to 21.39$)$ \\
Dual initial therapy* & 0.23 & $(0.07$ to 0.74$)$ \\
\hline
\end{tabular}

${ }^{*}$ Dual initial therapy consisted of a beta-lactam and a macrolide in the initial prescribed regimen for at least $48 \mathrm{~h}$

therapy and three were on monotherapy $(\mathrm{P}>0.2)$. Other factors, such as age, congestive heart failure, chronic obstructive pulmonary disease and immunosuppression, did not increase mortality risk (Table 3).

Penicillin nonsusceptibility (strains categorized as intermediate or resistant to penicillin) was not associated with increased mortality (one of 10 [10\%] intermediate or resistant strains versus 14 of 85 [16.5\%] susceptible strains for sensitive strains). There was no resistance to ceftriaxone, and five strains were resistant to cefuroxime (all in the 1998 to 2000 group in which cefuroxime was not used). The most common serogroups found during this study were: $14(n=16)$, 9V $(\mathrm{n}=15), 4(\mathrm{n}=11), 23 \mathrm{~F}(\mathrm{n}=7), 6 \mathrm{~B}(\mathrm{n}=6), 3(\mathrm{n}=6), 18 \mathrm{C}$ $(\mathrm{n}=5), 19 \mathrm{~F}(\mathrm{n}=4), 22 \mathrm{~F}(\mathrm{n}=4)$ and others $(\mathrm{n}=8) ; 13$ strains were not typeable. Mortality was not associated with a specific serotype.

\section{DISCUSSION}

Bacteremic $S$ pneumoniae pneumonia is the most common cause of mortality in CAP. In one study looking at 108 cases of bacteremic S pneumoniae pneumonia (19), the mortality rate was $24.1 \%$, which was much higher than in CAP without bacteremia. Studies (20-21) have demonstrated the importance of initiating the proper antibiotic therapy rapidly. In one 
study (21), patients who were given an antibiotic within $8 \mathrm{~h}$ of arrival did better than those who waited longer for their first antibiotic dose. This was not an issue in the present study because all the patients had at least one dose within this time frame. Gleason et al (20) also demonstrated that in elderly patients, the initial antibiotic choice had a key impact on the 30-day survival rate (20). Patients who were treated either with a combination of a cephalosporin and a macrolide or with a fluoroquinolone alone did better than those who received monotherapy with a beta-lactam, even after adjusting for risk factors such as age and comorbidity.

The finding that combination therapy may be superior to monotherapy in severe CAP cases may be explained by different factors: a better coverage of atypical microorganisms and action at two different sites in the bacteria (the cell wall for beta-lactams and inhibition of protein synthesis for macrolides). Furthermore, macrolides have been shown to have some anti-inflammatory properties. They reduce the production of interleukin-8 and tumour necrosis factor-alpha (eg, erythromycin has been shown to reduce the adherence of S pneumoniae to respiratory epithelial cells) (22). Beta-lactams and fluoroquinolones act as bactericidal agents and destroy a large number of bacteria in a short amount of time, thus, releasing intracellular components capable of increasing inflammation. Macrolides potentially decrease the production of virulence factors by inhibiting protein synthesis. This has been shown for severe Group A Streptococcus infections in which clindamycin, acting as a protein synthesis inhibitor, may add a significant benefit to treatment (23).

There is some controversy regarding decreased virulence of invasive $S$ pneumoniae strains. Several large scale in vitro studies (16) have shown lower levels of resistance to penicillin and macrolides among invasive strains. Levels of resistance have been significantly higher in isolates from the respiratory tract, eyes and ears. Some authors (24) have advanced the hypothesis that resistance may be associated with an increased energy cost for the bacteria, rendering the organism less virulent. There may also be a bias in surveillance studies of respiratory tract isolates, because they are most often isolated from samples taken in tertiary care centres from patients with chronic diseases who have received numerous antibiotic treatments (eg, chronic obstructive pulmonary disease) and from immunocompromised patients (eg, HIV, chemotherapy).

As shown in two previous studies $(9,10)$, the addition of a macrolide, mostly during the 1998 to 2000 period, had a significant impact on mortality. In the present study, bacterial resistance probably does not explain the difference in terms of mortality. Another study (25) demonstrated that resistance in bacteremic pneumococcal pneumonia did not have any significant impact on outcomes.

Waterer et al (9) also suggested that for bacteremic $S$ pneumoniae pneumonia, monotherapy of any kind may be suboptimal. A second study (10) showed a similar trend in Spain, where the addition of a macrolide to a beta-lactam regimen decreased inhospital mortality. All clinical studies comparing newer fluoroquinolones with older therapies were published with the intent of registration approval; therefore, high-risk patients were usually excluded. The vast majority of deaths were categorized as either class IV or V (18), which are generally excluded from clinical trials. The CommunityAcquired Pneumonia Intervention Trial Assessing Levofloxacin (CAPITAL) by Marrie et al (26) showed a better outcome for fluoroquinolones, but this may have been explained by the study protocol itself. Implementing an active and highly interventionist clinical pathway lead to better resource utilization. One study (27) showed an economic benefit for fluoroquinolone monotherapy over a combination treatment, but the vast majority of the cases were not severe CAP cases (26).

The arrival of a newly conjugated pneumococcal vaccine has the potential to decrease the number of invasive infections in the future and will likely have a positive impact on the incidence of bacteremia. However, the possibility of a switch from serotypes contained in the vaccine towards new ones has been raised (28). Better and earlier detection methods to rule out the presence of bacteremia at initial presentation will certainly help. Rapid methods based on DNA detection in blood are not far away and will make life easier for clinicians (29). The arrival of an $S$ pneumoniae urinary antigen test may be helpful in the future (30).

Although our study was a nonrandomized retrospective study, it confirmed the importance of initially adding a macrolide to a beta-lactam regimen for bacteremic $S$ pneumoniae pneumonia. Prospective studies comparing dual therapy regimens versus monotherapy are badly needed for severe hospitalized CAP. The main limitation resides in the extreme difficulty of recruiting enough patients with bacteremic pneumococcal pneumonia in emergency departments. Clinical trials comparing the newer fluoroquinolones with a combination regimen are also needed.

\section{REFERENCES}

1. Mandell LA, Marrie TJ, Grossman RF, Chow AW, Hyland RH;

The Canadian Community-Acquired Pneumonia Working Group. Canadian guidelines for the initial management of community-acquired pneumonia: An evidence-based update by the Canadian Infectious Diseases Society and the Canadian Thoracic Society. Clin Infec Dis 2000;31:383-421.

2. Marrie TJ. Community-acquired pneumonia. Clin Infect Dis 1994;18:501-13.

3. Bartlett JG, Mundy LM. Community-acquired pneumonia. N Eng J Med 1995;333:1618-24.

4. Fine MJ, Smith MA, Carson CA, et al. Prognosis and outcomes of patients with community-acquired pneumonia. A meta-analysis. JAMA 1996;275:134-41.

5. Austriam R, Gold J. Pneumococcal bacteremia with special reference to bacteremic pneumococcal pneumonia. Ann Intern Med 1964;60:759-76.

6. Torres JM, Cardenas O, Vasquez A, Schlossberg D. Streptococcus pneumoniae bacteremia in a community hospital. Chest 1998;113:387-90.

7. Bartlett JG, Breiman RF, Mandell LA, File TM Jr, for the Infectious Diseases Society of America. Community-acquired pneumonia in adults: Guidelines for management. Clin Infect Dis 1998;26:811-38.

8. British Thoracic Society Standards of Care Committee. BTS guidelines for the management of community-acquired pneumonia in adults. Thorax 2001:56(Suppl 4):IV1-64.

9. Waterer GW, Somes GW, Wunderink RG. Monotherapy may be suboptimal for severe bacteremic pneumococcal pneumonia. Arch Intern Med 2001;161:1837-42.

10. Martinez JA, Horcajada JP, Almela M, et al. Addition of a macrolide to a beta-lactam-based empirical antibiotic regimen is associated with 
lower in-hospital mortality for patients with bacteremic pneumococcal pneumonia. Clin Infect Dis 2003;36:389-95.

11. Lieberman D, Schlaeffer F, Boldur I, et al. Multiple pathogens in adult patients admitted with community-acquired pneumonia: A one year prospective study of 346 consecutive patients. Thorax 1996;51:179-84

12. Lonks JR, Garau J, Gomez L, et al. Failure of macrolide antibiotic treatment in patients with bacteremia due to erythromycin-resistant Streptococcus pneumoniae. Clin Infect Dis 2002;35:556-64.

13. Davidson R, Cavalcanti R, Brunton JL, et al. Resistance to levofloxacin and failure of treatment of pneumococcal pneumonia N Engl J Med 2002;346:747-50.

14. Weiss K, Restieri C, Gauthier R, et al. A nosocomial outbreak of fluoroquinolone-resistant Streptococcus pneumoniae. Clin Infect Dis 2001;33:517-22

15. Chow AW, Hall CB, Klein JO, Kammer RB, Meyer RD, Remington JS, for the Infectious Diseases Society of America and the Food and Drug Administration. Evaluation of new antiinfective drugs for the treatment of respiratory tract infections. Clin Infect Dis 1992;15(Suppl 1):S62-88.

16. Weiss K, de Azavedo J, Restieri C, et al. In vitro activity of a novel ketolide ABT-773 against invasive strains of Streptococcus pneumoniae. J Antimicrob Chemother 2001;48:407-9.

17. National Committee for Clinical Laboratory Standards. Methods for Dilution, Antimicrobial Susceptibility Tests for Bacteria that Grow Aerobically, 7th edn. Approved standard M2-A7. Villanova: National Committee for Clinical Laboratory Standards, 2000.

18. Fine MJ, Auble TE, Yealy DM, et al. A prediction rule to identify low-risk patients with community-acquired pneumonia. $\mathrm{N} \mathrm{Engl} \mathrm{J}$ Med 1997;336:243-50.

19. Watanakunakorn C, Bailey TA. Adult bacteremic pneumococcal pneumonia in a community teaching hospital, 1992-1996: A detailed analysis of 108 cases. Arch Intern Med 1997;157:1965-71.

20. Gleason PP, Meehan TP, Fine JM, Galusha DH, Fine MJ. Associations between initial antimicrobial therapy and medical outcomes for hospitalized elderly patients with pneumonia. Arch Internal Med 1999;159:2562-72
21. Meehan TP, Fine MJ, Krumholz HM, et al. Quality of care, process and outcomes in elderly patients with pneumonia. JAMA 1997;278:2080-4

22. Takizawa H, Desaki M, Ohtoshi T, et al. Erythromycin modulates IL-8 expression in normal and inflamed human bronchial epithelial cells. Am J Respir Crit Care Med 1997; 156:266-71.

23. Kaul R, McGeer A, Norrby-Teglund A, et al. Intravenous immunoglobulin therapy for streptococcal toxic shock syndrome - A comparative observational study. The Canadian Streptococcal Study Group. Clin Infect Dis 1999;28:800-7.

24. Gillespie SH. Antibiotic resistance in the absence of selective prssure. Int J Antimicrob Agents 2000;17:171-6.

25. Moroney JF, Fiore AE, Harrison LH, et al. Clinical outcomes of bacteremic pneumococcal pneumonia in the era of antibiotic resistance. Clin Infect Dis 2001;33:797-805.

26. Marrie TJ, Lau CY, Wheeler SL, Wong CJ, Vandervoort MK, Feagan BG. A controlled trial of a critical pathway for treatment of community acquired pneumonia. CAPITAL Study Investigators. Community-Acquired Pneumonia Intervention Trial Assessing Levofloxacin. JAMA 2000;283:749-55.

27. Dresser LD, Niederman MS, Paladino JA. Cost-effectiveness of gatifloxacin vs ceftriaxone with a macrolide for the treatment of community-acquired pneumonia. Chest 2001;119:1439-48.

28. Pelton SI, Dagan R, Gaines BM, et al. Pneumococcal conjugate vaccines: Proceedings from an interactive symposium at the 41st Interscience Conference on Antimicrobial Agents and Chemotherapy. Vaccine 2003;21:1562-71.

29. Zhang Y, Isaacman DJ, Wadowsky RM, Rydquist-White J, Post JC, Ehrlich GD. Detection of Streptococcus pneumoniae in whole blood by PCR. J Clin Microbiol 1995;33:596-601.

30. Murdoch DR, Laing RT, Mills GD, et al. Evaluation of a rapid immunochromatographic test for detection of Streptococcus pneumoniae antigen in urine samples from adults with community-acquired pneumonia. J Clin Microbiol 2001;39:3495-8. 


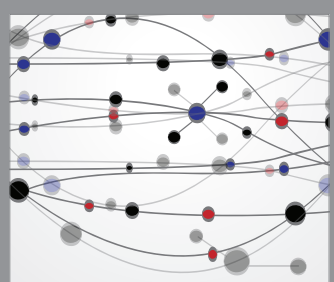

The Scientific World Journal
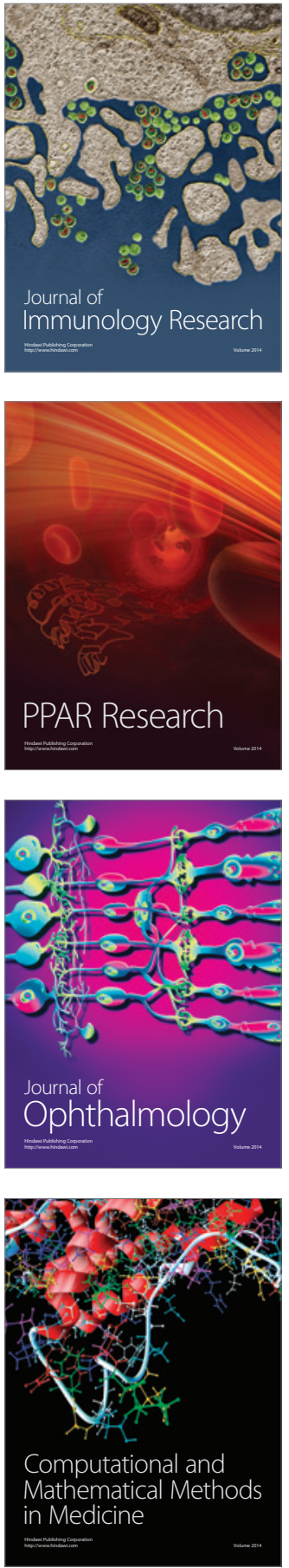

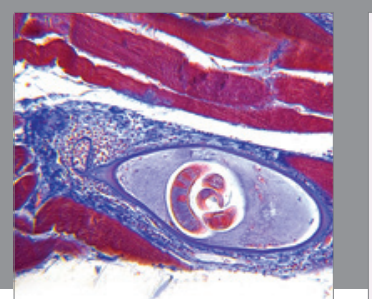

Gastroenterology Research and Practice

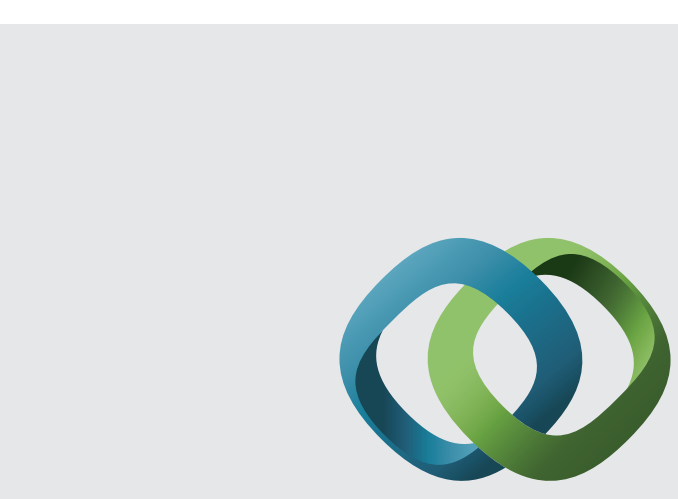

\section{Hindawi}

Submit your manuscripts at

http://www.hindawi.com

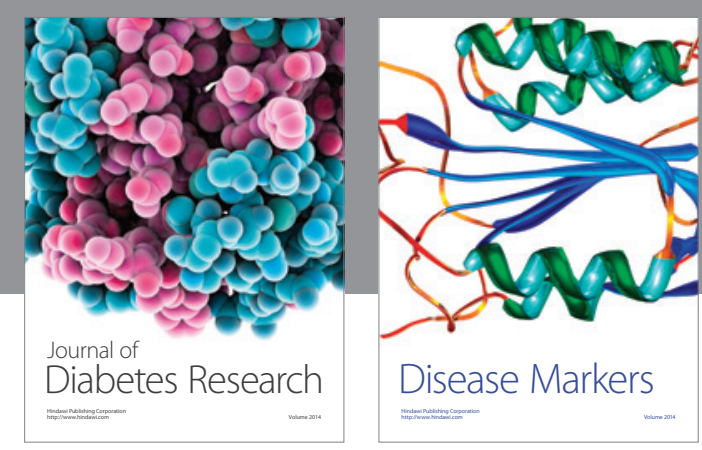

Disease Markers
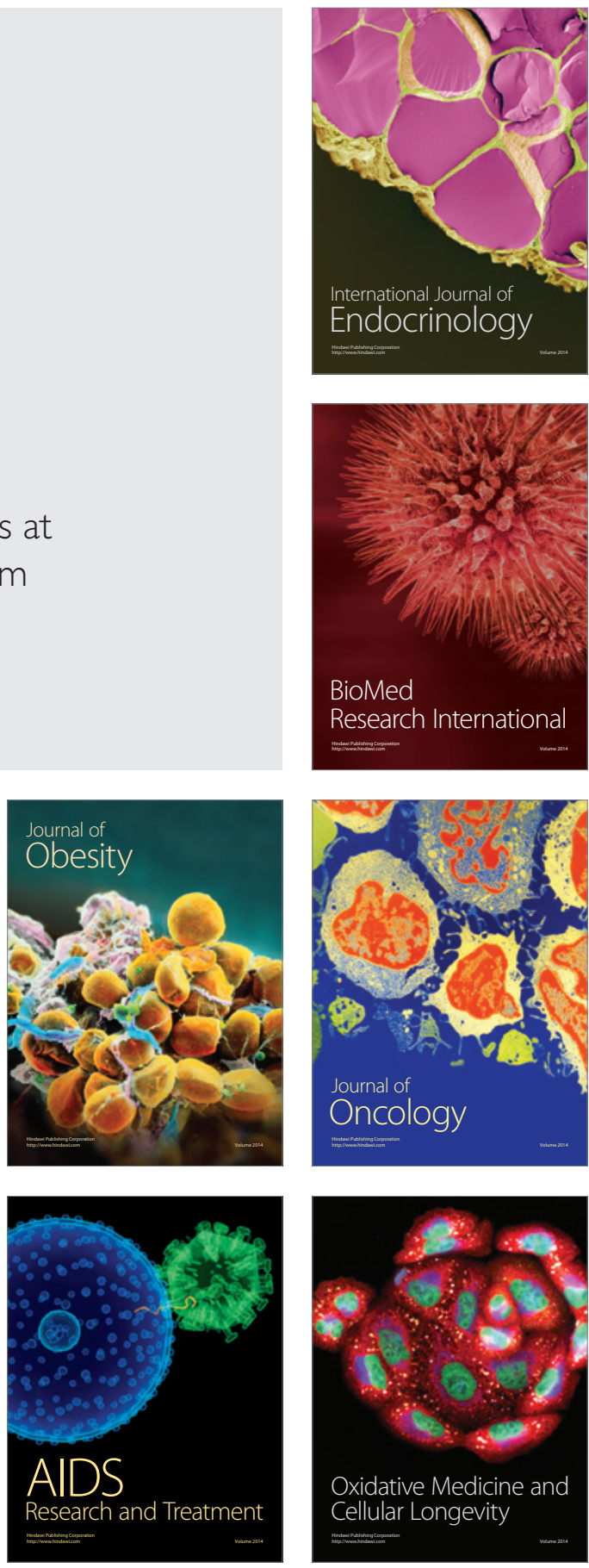